\title{
Roman Manipular Warfare as a Mega-Weapon of Antiquity
}

\author{
Andrey Krakovsky \\ Tacticus Capital LLC, New York, USA \\ Email: krakovsky@tacticap.com
}

How to cite this paper: Krakovsky, A. (2021). Roman Manipular Warfare as a Mega-Weapon of Antiquity. Voice of the Publisher, 7, 146-162.

https://doi.org/10.4236/vp.2021.74012

Received: September 15, 2021

Accepted: December 14, 2021

Published: December 17, 2021

Copyright $\odot 2021$ by author(s) and Scientific Research Publishing Inc. This work is licensed under the Creative Commons Attribution International License (CC BY 4.0).

http://creativecommons.org/licenses/by/4.0/

\begin{abstract}
We present a coherent picture of the functioning of a Roman infantry legion based on a systematic procedure of finding weak points in the enemy formation as a destination for persistent attacks. We conjecture that this tactic was a robust and resource-efficient way to victory. Its discovery could be one of the primary reasons for developing a manipular legion, a unique way of fighting that shaped Roman warfare.
\end{abstract}

\section{Keywords}

Roman Warfare, Battlefield Tactics, Manipular Legion, Nonlinear Response

\section{Introduction}

Roman system of warfare fascinated military observers and historians for over two millennia. What made it unbeatable on the battlefields across three continents, especially in pitched battles? What were the secret ingredients of the "manipular" formation that originated in the $4^{\text {th }}$ century B.C.? Why did Romans adopt a battlefield formation that was highly unorthodox and seemingly awkward at the time, and how did the Roman legion function?

We will reconstruct some of the tactics and actions of a Roman infantry battlefield engagement to show that during intermediate stages of a battle, the working of the legions served to determine weak spots in the enemy formation as points of more decisive strikes. These battlefield tactics were productive and provided a resource-efficient way to victory. We will argue that the Roman discovery of this dynamic warfare could be one of the primary reasons for universally adopting manipular legion as a tactical doctrine, regardless of an opponent's tactics, troops' composition, or battlefield terrain.

Our model contributes to an understanding of why Romans radically deviated 
from the phalanx, the most popular and accepted military formation in the Hellenic period, to create a versatile doctrine destined to become a "phalanx killer" while also not less effective against other looser formations. The aims and mechanics of Roman maneuvering that continue to fascinate researchers fit coherently into our picture. Even though the cohort system replaced manipular legion in its pure form towards the late Republic, more advanced military structures likely inherited elements essential to the legion's functioning.

Roman battlefield tactics' systematic and methodical nature may shed further light on the foundation of the notorious Roman bravado and their sense of military invincibility.

We will start by following existing academic work to show that the precise working of the Roman legions on the battlefield has indeed been a puzzle from the time of its emergence. We will attempt to reduce the complicated and involved process of ancient large-scale hand-to-hand combat to a shortlist of immediate aims and directives. Focusing on the most critical variables for winning an antiquity battle will provide us with a prototype battle plan. We will further use the historical material to reconstruct the actual maneuvers of the Roman maniples and reveal their place, sequence, and purposes in our picture.

\section{The Two-Millennia Puzzle}

The puzzle of Roman battlefield domination, especially in formal pitched battles, has been around for over two millennia. What enabled them to assemble an unbeatable military machine capable of taking on virtually any enemy? How could Romans battle poorly known opponents in complete confidence, often being significantly outnumbered, about one to five, with almost non-existent strategic intelligence or reconnaissance, and still achieve victories with at least a third of their army not involved in the combat (Goldsworthy, 2000: p. 55)?

Roman contemporaries and later researchers have been trying to uncover the secrets of the Roman military battlefield action, with the "recently renewed" interest from the Renaissance. Polybius is one of the most respected military sources back to the mid-Republic of the $2^{\text {nd }}$ century B.C. He rhetorically questions "why it is that the Romans conquer and carry off the palm from their enemies in the operations of war" and points out that "we may not put it all down to Fortune" (Polybius, 18.28).

Roman soldiers were legendary for "combat virtues." They include strict discipline, the stamina to keep their ground, ultimately enforced by a brutal decimation practice, aggressiveness, and an unbreakable spirit (Goldsworthy, 2000: p. 184). Personal bravery was raised to a level of a cult by an elaborate system of rewards and rebukes (Lendon, 2005: pp. 190-192). Even though combat virtues are essential qualities of a winner, a person with any amount of military training will attest that they cannot solely be responsible for consistently securing victory after victory. The conventional wisdom is that a victorious party needs to possess combat virtues in addition to a solid military strategy and tactics. 
Was it a coincidence, Polybius' prophecy, or his insight knowledge that from the time of his writings claiming superiority of Roman military techniques, the city-state continued successful military campaigning for several hundred years? During the Second Punic War, Rome lost three consecutive major battles to Hannibal's forces. Three Roman armies were virtually annihilated in these engagements: at Trebbia, at Lake Trasimenus, and at Cannae. Still, Rome continues hostilities and is eventually victorious. Were they delusional in their determination and bravery or persevered from the conviction that their battlefield doctrine is ultimately viable and will prevail in the end? Polybius unequivocally points to the latter: "It was not owing to their [Carthaginians] arms...but to the skill and genius of Hannibal [that these battles were lost, and] as soon as the Romans got a general of ability comparable with that of Hannibal, victory was not long [in waiting]" (Polybius, 18.28).

Romans were known to achieve their victories despite the inexperience of mid-and lower-level officers, military tribunes included, which hypothetically should not have combined well with the high requirements of their new and dynamic way of warfare (Goldsworthy, 2000: p. 52). Did battle-hardened lower-rank soldiers make up for this lack of experience? Could the primary function of these officers be to merely transmit orders from senior commanders, effectively constituting a communication chain necessary in dynamic regroupings without a real mandate of making their own decisions, and an extensive experience was not required to perform that task?

Polybius gives us a clear answer to what carried the Roman military machine, making it an antique equivalent of nuclear weapons. It was a "peculiar way of Roman fighting," a mega-weapon of manipular warfare. At its core was a systematic execution of a sequence of battlefield maneuvers adaptable to the circumstances of a particular battle.

The Roman army had adopted the manipular legion formation in the $4^{\text {th }}$ century B.C. during Samnite wars, reportedly to adapt to an unforgiving mountainous terrain of the highlands of Samnium. For Romans, this new formation replaced phalanx, a traditional fighting order in the Hellenic world (Fields, 2010: p. 41). By that time, the Roman army had already mastered the phalanx tactics acquired just over a century prior in the course of the Etruscan Wars, likely borrowing it from the Etruscans. New infantry formation (legion) had the army broken into many small rectangular groups (maniples) arranged in three lines in a chessboard-like structure with space between them. It was a radical departure from phalanx, a continuous densely packed fighting order. As seen by contemporaries, the existence of gaps in a battlefield formation generally compromised the frontline's integrity.

In his analysis of the Macedonian phalanx in the aftermath of the Roman victory over Philip V at Cynoscephalae, Polybius explains that any irregularly of the battlefield terrain, even as simple as ditches, tends to distort a phalanx' order. It deprived the phalanx of its principal asset of being an impenetrable wall of shields and pikes (Polybius, 18.31). A commonly accepted wisdom is that 
breaking up the continuous frontline into many disjoint segments, such as maniples, would save the phalanx from being disrupted by uneven terrain. Can we rest the case of the reason for breaking up legions into maniples? Was the manipular legion developed as a mere means of handling the irregular terrain, and more importantly, how did it function?

A close reading of the primary sources opens a Pandora box of questions. Critical questioning, insightfully presented in Lendon's work (Lendon, 2005: pp. 178-192), quickly reveals multiple discrepancies and contradictions within the commonly accepted views. Polybius acknowledges that "a well-formed phalanx is irresistible" and even further that it is "impossible to confront...so long as it retains its proper formation" (Polybius, 18.29). He describes each Roman front-row soldier as having to fight against ten pikes, which is a tantamount task even being protected by the Roman shield, scutum, characteristically extending over most of the body. From Polybius' description, going against a phalanx with a looser formation seems hardly advantageous.

More passages add to the confusion about the traditional interpretation of the working of the manipular formation. Polybius writes that even on flat ground, Romans would still use their manipular tactics (Polybius 18.31). In the same passage, he states that the key to this type of engagement is to "not risk his whole army upon one charge of the phalanx...but maneuver(s) for a time to avoid coming to close quarters in the engagement". Why wouldn't Romans deploy phalanx even on terrain that ideally suits it, especially having mastered phalanx tactics in their previous campaigns? What are those maneuvers, and what makes them so necessary? Why is a successful outcome a virtual certainty to Polybius if and only if performed: "it is easy to learn what will be the result"? Polybius's comments should be taken very seriously as he was a highly respected person, well-experienced in military matters, and would be unlikely to make unsubstantiated statements.

Polybius mentions a "mystery" maneuver [per Lendon, 2005] in his description of a battle against dauntlessly brave but likely loosely organized Gallic forces (Polybius, 2.33). Incidentally, drawing up a phalanx against this kind of enemy would seem natural in a Hellenic military tactician's book. Yet, Romans perceived their manipular formation more superior even in this situation. Polybius inconspicuously reveals the maneuver as he points out an error made by Roman consul Flaminius, an overall commander, of drawing his legions along the river bank, which "left the lines no room for their deliberate retrograde movements" so that the troops would back up into the river. According to Polybius, this blunder deprived Romans of "maneuver characteristic of Roman tactics." What was the purpose of a deliberate disengagement in the face of an enemy? Other sources reveal that such motion would be against all contemporary canons of warfare as any retreat had the potential of turning into a rout (Lendon, 2005: p. 182).

Another controversy exists around whether Roman legions fought while maintaining the gaps between different maniples or these gaps were closed im- 
mediately before engagement (Koon, 2010: pp. 2-7). Several sources describe a "posterior movement" maneuver of the second-line maniples (principes) to fill the gaps between the frontline maniples (hastati), thus producing a single unbroken line, much like a phalanx (Fields, 2010: p. 42; Keppie, 1984: p. 38). A rearrangement of this sort in direct proximity of the enemy lines would be a risky undertaking and most definitely required incredible agility while maintaining a high degree of coordination. Adding to uncertainty about this element of Roman tactics is whether conversion to a continuous frontline happened across the whole front of the Roman army, or involved only a part of it, thus forming a mini-front or a mini-phalanx.

The next piece of the puzzle involves the actual frontline action. Livy, in his depiction of the battle of Zama, in typical of his style dramatic terms, describes the attack as a consequence of repeated charges, steady advances, and withdrawals. The idea that the actual physical engagement consisted of repetitive combat surges, also known as a dynamic standoff, has been elaborated in the works of Sabin (Sabin, 1996, 2000) and Goldsworthy (Goldsworthy, 1996). What was the place of these intense, brutal, but relatively shallow attacks in a well-scripted operation of Roman legions? These attacks do not aim at immediately breaking the enemy ranks as they do not appear to carry enough momentum and weight. Were they pursued opportunistically in different front areas to cause disorder and confusion (Koon, 2010: p. 82), or was there a more fundamental reason behind them?

We will attempt to arrive at a set of tactical goals and formalize methods to achieve them in a pitched battle of antiquity to answer these questions.

\section{Search for the Weakest Point}

Mass hand-to-hand battle must have been a very complicated business in many dimensions. It involved logistical, military, physical, psychological, social (Lendon, 2005: pp. 184-192), and likely many other intertwining aspects. In determining the origins and functioning of a manipular legion, we will attempt to deconstruct a typical battlefield action to arrive at an idealized version containing only the most critical factors.

Our analysis focused on pitched battles. These are head-to-head, toe-to-toe battles where neither party has any strategic advantages such as terrain, encirclements, or ambushes. The only way to victory in this type of engagement is to go forward and break the enemy's formation. We choose this type of hostilities for two main reasons. Firstly, it was the most prominent and decisive element of Hellenistic warfare, often culminating an entire campaign (Goldsworthy, 2000: p. 55). Secondly, we believe that pitched battles forged and perfected the tactics of the manipular legion. After all, fighting pitched battles was the most formidable skill of the Roman army.

Let us suppose we are facing an enemy formation, pictured by an oval in Figure

1. The overall purpose of such battles back to the days of antiquity, rather 
Enemy

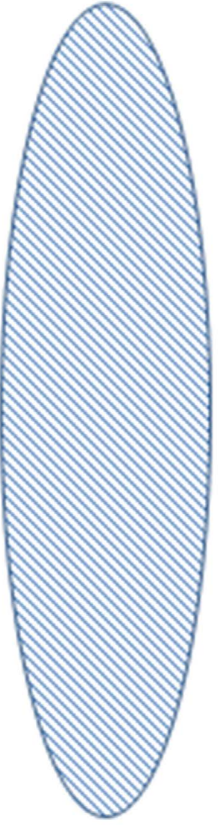

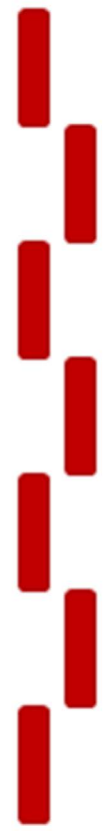

Romans

Figure 1. Opposing troops formations.

inhumanely, was inflicting the highest number of casualties. Battles rarely, if ever, were fought for any more sophisticated reasons other than destroying the enemy's fighting force (Goldsworthy, 2000: p. 55).

What would be a set of immediate objectives in a pitched battle? Only a small number of casualties occurred while both parties were physically facing each other while maintaining their respective fighting orders, around 5\% (Goldsworthy, 2003: p. 184). An absolute defeat came only when the ranks of one of the parties would break, allowing the soldiers of the opposite side to penetrate the opponent's formation in numbers. It quickly resulted in a rout where fleeing soldiers would turn their backs, significantly less armored and protected, to the overpowering side, and mass casualties would follow. The battle's strategy, i.e., the overall objective, was relatively straightforward and consisted merely of breaking the enemy's ranks.

The tactics, i.e., the means of achieving this strategic goal, is a significantly more complicated issue. In our idealized pitched battle of Figure 1, the most apparent option is crushing the enemy with an overwhelming force across their front. A massive strong enough frontal blow will break the enemy's lines at some part of their front, allowing our troops to penetrate their ranks and readily rout the opponent. These "brute force" tactics would roughly correspond to that of a phalanx. Polybius describes phalanx as effectual and irresistible, though not without flaws. It also naturally requires significant resources, especially against an enemy familiar with the phalanx tactics.

Is there another way of breaking enemy lines that do not require such an overwhelming commitment in troops? Opposing enemy lines usually look intense and frightful on approach, sounding loud horns, wearing animal-like flair, 
producing an intended psychological shock (Goldsworthy, 2003: p. 84). However, regardless of how uniform and firm the enemy's formation appears, it has strong and weak sections. Relative strength or weakness of a particular part of the front has to do with the training, arms, or motivation of soldiers forming these parts, among many other reasons. Knowledge of the location of a weak segment in the enemy's front allows directing a decisive blow there and potentially breaking the enemy's ranks with minimal resources. Once the enemy formation breaks, the rest of the enemy's army usually joins the rout, and victory follows without an attack on other, more robust parts of the front.

The location of the enemy's vulnerable sections is an obvious key to victory, but how could they be discovered? Just eyeballing the enemy's front for what could appear a softer target may be misleading. It is unlikely that the opposing side's general would line up the troops so that the weaker divisions are easy to identify. Scientific response analysis helps in telling a vulnerable point A from a secure point $B$ in an enemy's front [Figure 2].

Every executed attack produces an enemy's pushback or response. As the strength of attack grows, the enemy's reaction does not necessarily increase proportionally. Correspondence of the level of response to the attack strength for points A and B is in Figure 3. At point A of the enemy's line, the enemy's reaction does not keep up with the intensifying attacks. The enemy's lines are likely to break with more potent attacks at point A, making A a weak point. The picture at point $B$ is the opposite: more intense assaults make the enemy's response progressively stronger. Increasing attacks there will likely be overwhelmed, making B a strong point of the enemy's front.

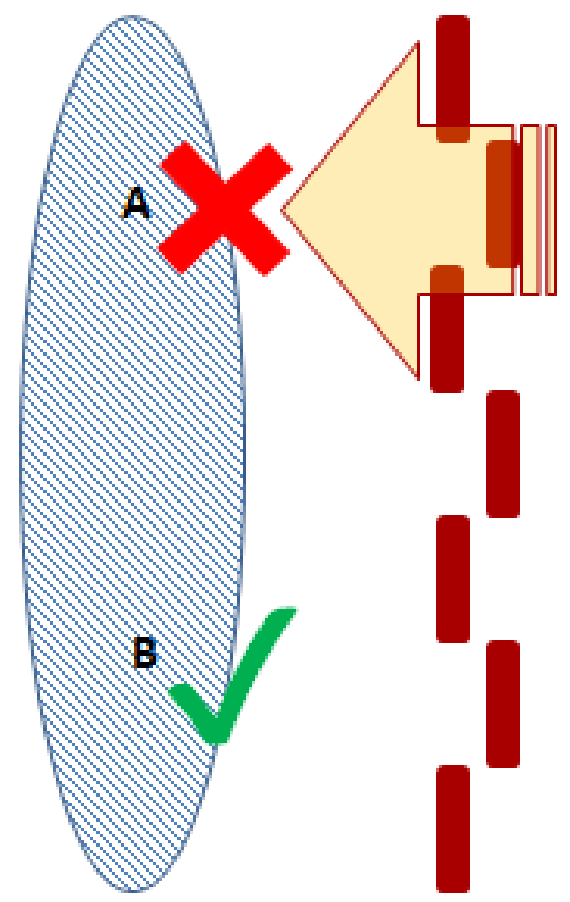

Figure 2. Sampling for a weak point. 


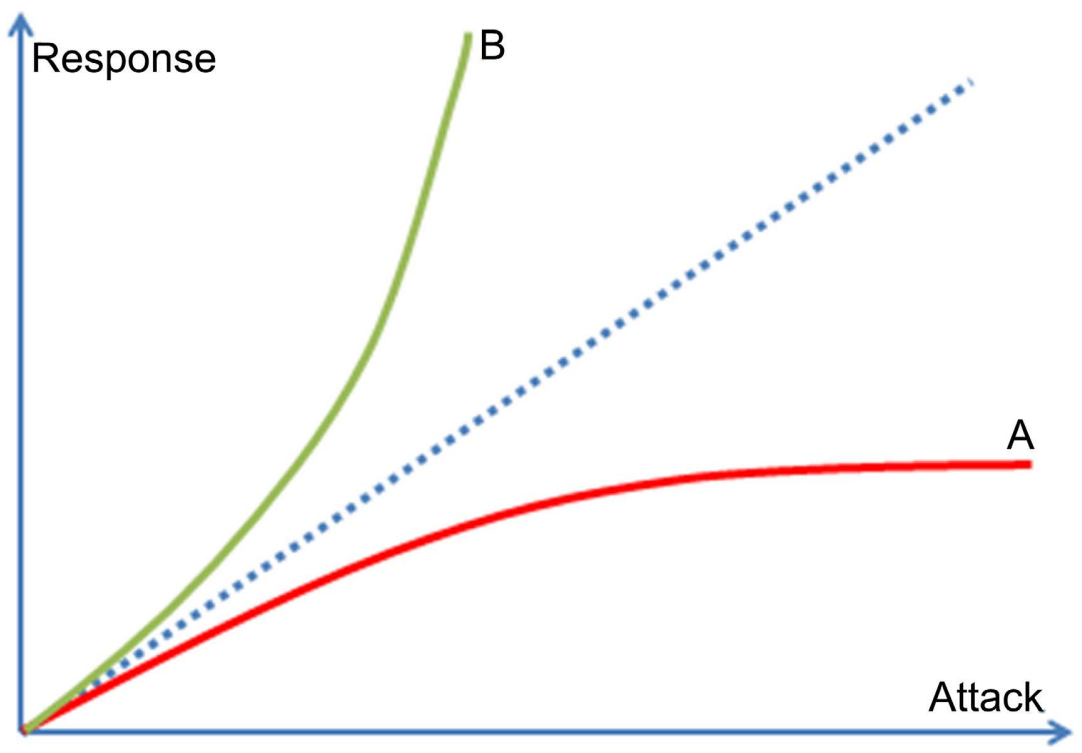

Figure 3. Response to attacks on weak and strong points.

Choosing between aiming a decisive blow to points $\mathrm{A}$ and $\mathrm{B}, \mathrm{A}$ is a definite answer. The enemy can be overrun at $\mathrm{A}$ as their resistance flattens out with more potent attacks. Oppositely, committing significant resources to assaults at point $B$ could be devastating as the enemy's overwhelming response will deflect them.

Recent work on non-linear response (Krakovsky, 2016, 2018) describes the scientific context for identifying points like A and B. A careful observation of how the enemy's lines recede or advance at a particular frontline section under the surges of combat action during dynamic standoff reveals the level of resistance that that part of the front can provide in a more decisive attack. It spells a recipe for sampling the enemy's frontline with smaller exploratory strikes in different sections to map out the vulnerable areas. This exploratory action does not require a commitment of a massive force at any particular place. Delivering more persistent attacks to the discovered weak parts of the enemy's front will maximize the likelihood of success.

Our conviction is that Romans had discovered this effective and resource-efficient technique of locating weak points in the enemy's lines early on. In our view, this discovery led to the development of the manipular legion and was the primary reason behind its revolutionary structure and functioning.

\section{Primary Sources}

If a written volume of a "Battlefield Companion to a Roman General" is unearthed with detailed instructions on tactical objectives in a battle, our task of figuring out the functioning of a Roman legion would be drastically simplified. Meanwhile, we are left to work with existing primary historical accounts in the absence of such a find. Since no historical document with a detailed description of Roman battlefield tactical aims and goals exists, our job consists of matching the patchwork of maneuvers reports in various battles fought by the Roman 
Army to see if they confirm or deny our model.

Before aligning the model with the historical evidence, a reflection on the primary historical sources is in place. We have good records from Polybius (Polybius) and Livy (Livy). (Other, likely very relevant Polybius' books such as Tactics are, unfortunately, lost.) Although written much later than the time of Mid-Republic, Livy's work still contains many accounts of battles of those days. His description of repetitive combat surges (Koon, 2010: p. 56) is indispensable in our realization of Roman tactics.

Polybius is a more complex author. He came from Greek nobility and enjoyed a high societal status in Rome, despite being one of the Achaean noble hostages taken due to what Romans perceived as his fathers' Lycortas and his underwhelming commitment to Rome. Polybius was highly knowledgeable of military matters. This expertise came from his political class upbringing in Greece and a personal closeness to the top Roman military commanders. He was an experienced military observer in many Roman battles during the Third Punic War, traveling in the company of Scipio Aemilianus, his aristocratic student and later one of the best-known Roman commanders (Koon, 2010: p. 5). It would be unthinkable to assume that Polybius did not know the exact purpose of every element of Roman tactics and its place in the overall scheme. As we reflected in Section II, Polybius' prediction of Roman military domination lasted for many centuries from his writings. Such insight could only come from his detailed knowledge of the Roman tactical approach and a profound understanding of the superiority of its principles.

Why wouldn't Polybius tell us precisely what winning tactical objectives were, what was the purpose of the maneuvers, when and in which sequence to execute them, and how the manipular legion worked (Koon, 2010: p. 2)? Polybius certainly had that knowledge. The only and commonly accepted rationale he explicitly offers is that Roman legions are better in uneven terrain, conditional on undertaking specific maneuvering (Polybius, 18.31)?

We do not believe the primary reason for the development of manipular warfare was its better terrain adaptability. It could have been a ruse, as thinking that one should draw broken formation only because of terrain deflects from the focus on the core functioning of the maniples. It is possible that the mountainous lands of Samnium gave Romans initial ideas of a coordinated discontinuous frontline and could be the first impetus in the mastering of manipular warfare. Polybius is transparent that if maniples go against a phalanx without performing some special maneuvers, the result could be devastating because phalanx is a formidable formation (Polybius, 18.29-31). The specifics of the maniples' maneuvering were essential to Roman victories, and it is difficult to imagine that a contemporary history book would reveal their exact working. Thus, an attempt to copy Roman formation without a clear understanding of its functioning would fail on the battlefield.

Still, Polybius was an intellectual, a member of the Scipionic Circle debating philosophy, literature, and social ideas. As "a crude and utilitarian rationalist," 
Polybius wanted to reach future generations with his historical and political insights (Walbank, 1957: pp. 6-16). They communicated crucial aspects of the revolutionary Roman battlefield technique, most likely without explicitly revealing a blueprint of its working. With or without intent, Polybius leaves definitive clues to the puzzle of the functioning of the manipular legion in his text through occasional comments on military tactics or glimpsing descriptions of special tactical moves as they occurred in particular battles. These clues need to be collected, deciphered, and arranged into a coherent picture.

Polybius must have been a person of incredible intellect. Only such a person could gain admission to the highest echelons of Roman society without coming from a position of a robust political standing within the Roman aristocracy. His ability is readily evidenced by his Histories being carefully thought-out and organized, containing a proper amount of historical facts, scrupulous detail, and insightful analysis. A high degree of deliberation put into Histories required it to be read word-by-word and digested almost like a legal document rather than a historical novel. Analyzing the passage that is commonly accepted to attribute the primary reason for the Roman formation to uneven terrain (Polybius, 18.31) with a lawyer's mindset, we can notice that Polybius never actually states that. He does explain why rough terrain interferes with phalanx's order but is far from claiming that it yields phalanx ineffective. In the same passage, Polybius is unequivocal that Romans will still employ their legions even on the most suitable for phalanx terrain.

\section{Manipular Warfare}

We will now turn to historical accounts to arrive at a possible realization of our picture of the deployment of Roman manipular legions.

One critical evidence of maniples' action is that attacking only a part of the enemy's front was a characteristic feature of Roman warfare. According to Polybius, "The Romans do not...attempt to extend their front to equal that of a phalanx...some of their divisions are kept in reserve, while others join battle with the enemy at close quarters" (Polybius 18.32). This passage shows that Romans create a front, but the front extends over a fraction of the enemy's frontline, akin to a mini-phalanx. The purpose of making the mini-phalanx is to sample the facing segment of the enemy's front for its strength and integrity. By saying that some of the Roman force was "in reserve," Polybius likely means it is not engaged in the immediate exploratory action.

Our focus will be the intermediate part of a battle. It occurred after an initial overture of skirmishing of light troops such as javelin throwers and slingers (velites) intended to disrupt the enemy's spirit and cause some amount of disorder in the enemy's lines. The intermediate part of the battle could last for a long time, up to several hours (Koon, 2010: pp. 2-7). During this phase of the fight, the maniples performed one of their most essential roles in figuring out the weakest part of the enemy's line. 
At the battle's onset of the middle phase, the enemy would typically face a chessboard formation of Roman legions, as shown in Figure 1. We show only the first two of the three lines of the Roman army, hastati, and principes, as often they were the only ones carrying the battle with the last line of the most battle-hardened and experienced troops (triarii) unengaged. Particular circumstances of engagement could result in modifications of the chessboard formation. In the Battle of Zama, Roman general Scipio Africanus decides to position them consecutively. Still, these modifications do not alter our overall scheme of how the legions functioned.

Upon the start of the intermediate phase of a battle, Roman maniples would form a partial phalanx against a segment of the enemy's lines, possibly using the "posterior movement" or similar maneuver, when principes, the second line of the maniples, would step into the gaps between the hastati, the front line [Figure 4]. Upon completing a mini-front, dynamic standoff in that part of the front would commence. During these shock attacks, commanding generals would watch the response of the enemy lines at that segment. We could only speculate what they were looking for; most likely, it was the rate of recession and quick recovery, or in the most disadvantageous case advance, of the enemy lines in that part of the front. Repeated surges of action of the dynamic standoff served as a sampling tool revealing potential incremental increase or decrease in the amount of enemy's resistance as the attack strength would grow.

It could be that a quick discovery of the weak spot in the enemy's formation results in the immediate attack at that location without sampling the rest of the enemy's front. More typically, after getting an idea of the strength of a particular segment of the enemy's order, Romans would sample other parts of the frontline. In that event, the maniples forming a mini-phalanx on the left part of
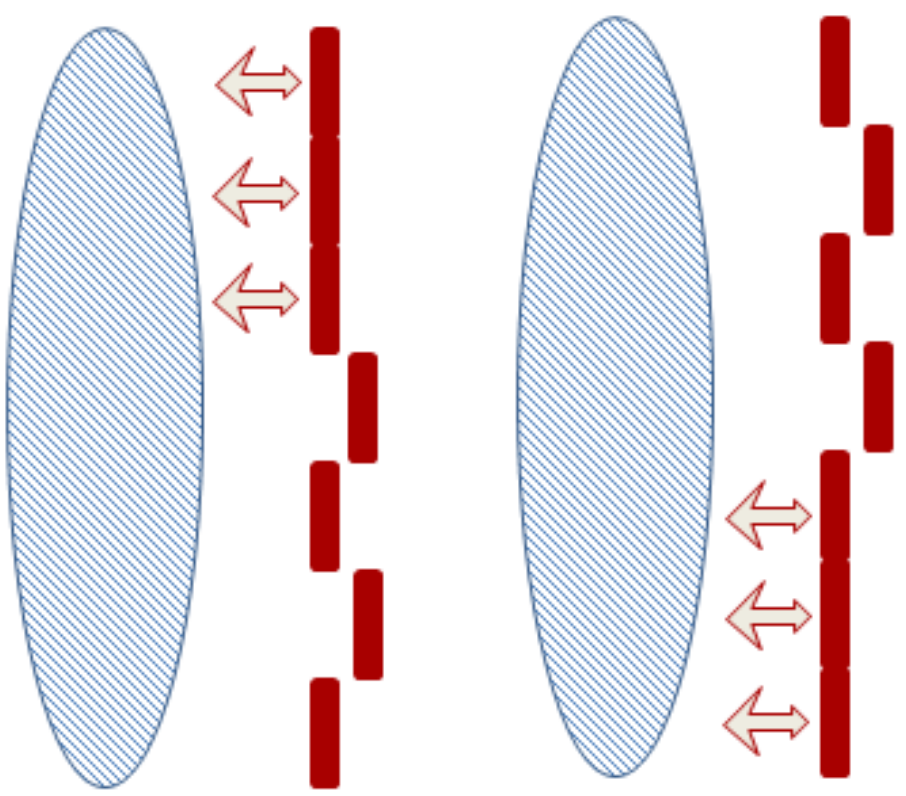

Figure 4. Formation of mini-phalanxes for sampling. 
Figure 4 would have to disengage back into their original formation. It corresponds to Polybius' description of the mystery "backward movement" maneuver discussed in Section II. Meanwhile, a similar mini-phalanx would be formed in the same fashion in another part of the front to measure the enemy's level of resistance there.

As the intermediate stage of the battle progressed, the enemy front was sampled in many places (Koon, 2010: p. 83) to find the weakest ones so that the final attack or attacks have the highest likelihood of success while involving the smallest amount of resources. To detect such spots, Romans would have to keep assembling mini-phalanxes in different parts of the front by combining their maniples much like Lego blocks. It is reflected in Plutarch's description of the battle of Pydna as the legions "fought several partial battles" rather than making "one general attack" (Plutarch, Aemilius Paulus). This systematic sampling was crucial to the functioning and success of the Roman manipular legion.

\section{Filling the Gaps}

Our picture allows unifying the controversies of Section II into a coherent description of manipular engagement. In agreement with Polybius, our theory of working manipular legions rests on constant maneuvering, continuous re-shaping of the frontline, and keeping initiative while exploring the enemy for weak points (Polybius, 18.31). We also explained the necessity of the backward maneuver as a means of disengagement to gain an opportunity to sample other parts of the enemy's front.

Substantial regroupings during the battlefield action were unusual and considered risky in a Hellenic world as the basic rule of the fight was "keeping it simple" (Lendon, 2005: p. 182). The necessity to undergo constant regroupings in assembling new mini-phalanxes and disassembling retreating ones while maintaining the overall pace of the battle required enormous coordination on a massive scale, and thus a complex chain of command. It may be the primary reason the Roman army was known precisely for its overwhelming number of mid-and low-level officers and a multi-layered command structure (Goldsworthy, 49). The sophisticated officer structure could be more of communication than an actual command chain where lower officers would have a mandate for making their own battlefield decisions. A fast and dynamic style of manipular warfare most definitely required efficient communications so that an order for action would reach soldiers quickly and simultaneously. Someone in a communication chain responsible for merely transmitting orders rather than command would require less military experience. It is another rationale that might lie behind the relative inexperience of the lower-ranked Roman officers.

The repeated attacks of the dynamic standoff and careful observation of their effect on the enemy lines were crucial to the manipular tactics. They provided a productive and resource-efficient way of sampling an enemy formation for the strength of its response. Thus, the dynamic standoff was inherent to the mani- 
pular tactics as it was the ultimate end-tool for revealing the location of the decisive attack.

Until now, the third and last line of Roman maniples consisting of the most experienced troops, the triarii, were left out of our discussion. We did it for clarity and because in most battles, the first two lines of maniples could carry the fighting entirely on their own with triarii unengaged. They would typically rest in their characteristic pose of a "quiet mountain" kneeled on one leg and protected by a shield (Livy, 30.32-36). They would come into action only if the first two lines of the Roman formation failed as a "last hope" for the army, suddenly "rising out of the earth" (Livy, 8.8). Roman proverbial "it comes down to triarii" signified a situation requiring extraordinary effort or dire.

Accounts of triarii battle tactics are even more sparse. We conjecture that overrun hastati and principes would regroup into a new line of maniples in front or behind triarii. The army would continue executing manipular tactics with a newly created two-line formation: triarii and what remained of hastati and principes.

Progressive engagement of a legion's lines is echoed in (Livy, 8.8), where he describes how the inner lines of troops come into action as the outer lines fail, referred to as the "line replacement." Livy's description is general and somewhat trivialized as it lacks details of movement dynamics and specifics of maneuvering, either intentionally as he presents just an overall scheme or due to limitations of his military background.

Even though we focused on an intermediate phase of a pitched battle as we considered it to be the most illustrative for the functioning of manipular warfare, the final stage of hostilities could look quite similar. The decisive blow to an enemy's weak enemy spot did not have to be a non-stop push. It could look identical to the action surges of the dynamic standoff, although much more concerted and at a significantly elevated intensity and impetus. Some of Livy's material suggests that (Livy). In our representation of response vs. attack, this way of dealing the decisive blow would achieve comparable results to a continuous push, probably with fewer resources.

The idea of segment-wise sampling of the enemy's frontline almost immediately brings one to the necessity of a discontinuous Lego-like formation that quickly regroups to form mini-fronts. Let us imagine sampling a particular part in the enemy formation with a phalanx. It would require the phalanx to bulge in the direction of the intended target [Figure 5]. Such a scenario is impractical, and a necessity to break up the lines into the typical Roman chessboard formation for these exploratory attacks is evident.

It is logical to believe the manipular tactics originally were conceived due to the necessity of fighting in the mountains where unforgiving terrain limited each party's attacks to only a fraction of the enemy's front. The full potential of the manipular system on any ground could reveal itself later.

The discovery of an alternative, efficient and robust way of breaking the enemy ranks in pitched battles led to adopting the manipular legion as a dominant 


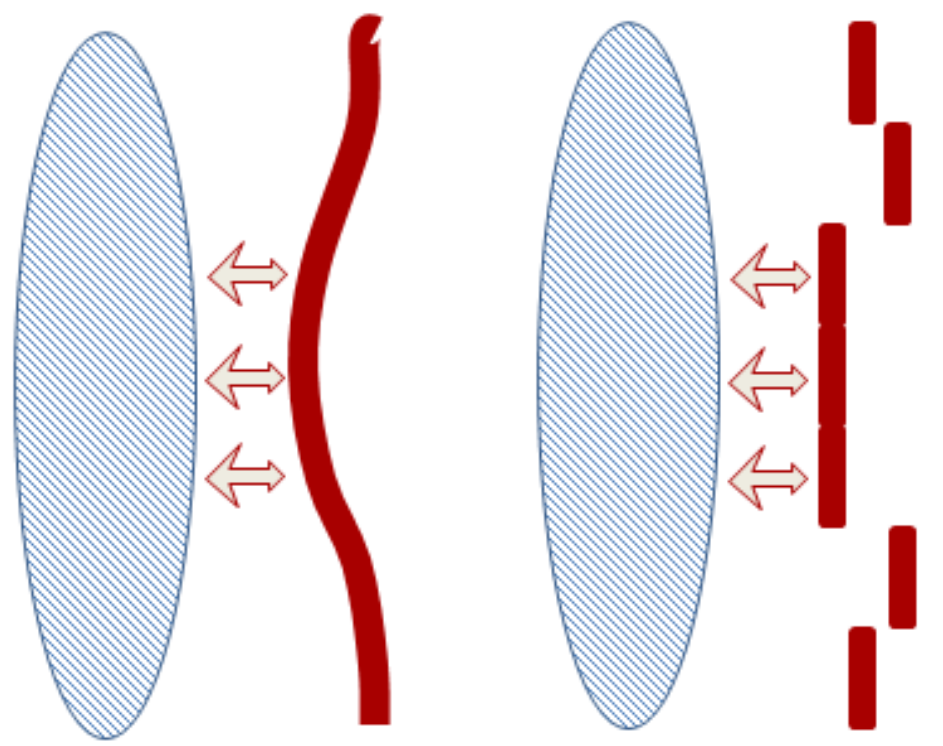

Figure 5. Impossibility of enemy line sampling by a continuous phalanx.

Roman military doctrine. This methodic combination of battlefield tactics worked well and was enormously productive. It could be behind a Roman sense of eventuality of the military outcome, lack of concern for being outnumbered (even outnumbered Romans often were victorious with only a fraction of army engaged in action), and casual attitude to military intelligence and reconnaissance. Romans knew they possessed a mega-weapon of the antique world, and it was this realization, not a superficial bravado, that gave Rome faith in her might and made her persevere in the face of her gravest threats in the course of numerous wars.

\section{Conclusion}

We presented a picture of the battlefield deployment of the Roman legionnaire army during a pitched battle. We argued that the prime purpose of the manipular action was to sample the enemy formation to determine its weakest spot, a target of the final decisive attack. The tactics of first discovering and then striking the most vulnerable part in the enemy formation were revolutionary developments in ancient warfare from then-prevalent phalanx. It enabled achieving victory efficiently, consuming significantly fewer resources and effort. It was a mega-weapon of antiquity.

Many sparring theories of how the Roman legions worked, such as whether they fought with or without gaps, dynamic standoff, the mechanism of line replacement, and many more, reflect the diversity of opinions on the subject. One of the reasons for this lack of consensus could be that most of the models describe specific elements of a multifaceted and dynamic process, each reflecting only a part of the overall picture and being correct within its context. Our view organically unifies them into a single coherent scheme of battlefield engagement.

The very structure of Roman formation of a chessboard of maniples was ne- 
cessary for continuous regrouping to form partial frontlines, or mini-phalanxes, at different points along the front. During this action, maniples were combined and recombined, much like Lego pieces. The "posterior movement" maneuver could achieve that. This mystery maneuver served to disengage from a sampling of a particular enemy front segment and disassemble mini-phalanx back into its maniples subsequently. It restored the original formation so that the maniples could be recombined again at a slightly different part of the front. The repeated surges of action of the dynamic standoff are an inherent part of our picture as they serve as an ultimate sampling tool of the enemy's lines.

Seemingly over-structured Roman chain of command fits in our picture. Active maneuvering during a close-quarters hand-to-hand battle required enormous coordination. Order to change position needed to reach the soldiers of a maniple very quickly and simultaneously. A vast body of officers likely served as a chain of communication rather than command. Officers of the chain were responsible for transmitting orders rather than making their own decisions. A well-documented duplication of the officers' duties was necessary to prevent the battle casualties from disrupting the communication line.

It is reasonable to believe that fighting in the highlands of Samnium helped Romans discover manipular tactics. Its rough terrain does not allow attacks across the whole front, a staple of the phalanx warfare. Instead, it must have forced the Roman army to resort to attacking only segments of the Samnites army by forming mini-fronts. This necessity could have given Roman commanders an initial idea of more effective battlefield tactics. Repeated action surges of the dynamic standoff to sample the enemy's front could occur naturally, as it has always been an element of the frontline engagement since the time of warbands, although in less organized fashion (Fields, 2010: pp. 30-32; Goldsworthy, 2003: p. 184). Romans likely perfected it by coordinating and articulating these surges to maximize their destructive power (Koon, 2010: p. 56; Livy, 30.32-36). Thus, manipular warfare emerged by putting several existing military tactics and tools together in a novel way to arrive at an unbeatable combination.

Watching Roman legions in action must have been an exhilarating spectacle. One can only imagine the sight of maniples forming into mini-fronts, attack surges, and then stepping back and re-forming again in different parts of the frontline. Battle choreography must have been confusing and puzzling to anyone without a clear understanding of the purpose of these motions. The battle's losing side could describe how the engagement was lost but would hardly be aware of the exploratory work that went into delivering a final attack. Because of the subtlety of the exploratory action, the rationale for the decisive strike might be escaping historical accounts as well. Any factual report primarily focuses on the visually evident strategic gains or losses during a battle with little justification for what went into decisions to attack, their placements, and military means or exact tactical reasons for them.

We described a prototype engagement blueprint, not a dogmatically rigid 
scenario for any battle. Commanding generals inventively adapted manipular tactics to the circumstances of each particular encounter. Principes could sometimes be directly behind instead of in-between hastati. Spaces between the maniples of hastati could be filled by light troopers (velites), as in the case of the battle of Zama (Livy, 30.32-36). Many other variations depended on the specifics of an engagement. Still, we believe that any Roman infantry involvement employed the fundamental principles of manipular warfare to a large extent.

We conjecture that the development and subsequent perfection of manipular warfare could have social and political implications. They were aware they could lose a battle or two, or an army or two, as happened in the Second Punic War. However, Romans knew that they possessed an antique equivalent of nuclear weapons in their military tactics and eventually prevailed. This realization could be behind their notorious military bravado and an unshakable belief of the eventuality of the ultimate victory in their military campaigns. This insider knowledge is behind Polybius' prophetic prediction of Roman military superiority, which lasted for many centuries from his writings.

\section{Acknowledgements}

The author is deeply indebted to Ted Szadzinski of Kings College London for his insights and guidance through primary and academic literature. Special thanks go to Dr. Nic Fields and Prof. Michael Peachin of New York University for the critical reading, suggestions, and corrections to the manuscript and for sharing their knowledge and views on the ancient battlefield engagements and specifics of Roman history.

We would also like to thank Dr. Adrian Goldsworthy and Prof. Phil Sabin for their interest in this work, help, and valuable suggestions. Last but not least, Prof. Oleg Prezdo for discussions of the scientific aspect of this work.

\section{Conflicts of Interest}

The author declares no conflicts of interest regarding the publication of this paper.

\section{References}

Fields, N. (2010). Roman Battle tactics 390-110 BC. Osprey Publishing.

Goldsworthy, A. (1996). The Roman Army at War. Clarendon Press.

Goldsworthy, A. (2000). The Punic Wars. Cossell \& Co.

Goldsworthy, A. (2003). The Complete Roman Army. Thames \& Hudson.

Keppie, L. J. F. (1984). The Making of a Roman Army. Batsford.

Koon, S. (2010). Infantry Combat in Livy’s Battle Narratives. BAR Publishing. https://doi.org/10.30861/9781407306322

Krakovsky, A. (2016). Response Properties of Self-Improving Systems. The Journal of Chemical Physics, 144, Article ID: 134107. https://doi.org/10.1063/1.4945423

Krakovsky, A. (2018). Master Equation for Coase-Time Microscopic Dynamics. AIP Ad- 
vances, 8, Article ID: 085301. https://doi.org/10.1063/1.5041379

Lendon, J. E. (2005). Soldiers and Ghosts. Yale University Press.

Livy, T. The History of Rome. Perseus Digital Library.

Plutarch. Parallel Lives. Perseus Digital Library.

Polybius. Histories. Perseus Digital Library.

Sabin, P. (1996). The Mechanics of Battle in the Second Punic War. Bulletin of the Institute of Classical Studies, 41, 59-79. https://doi.org/10.1111/j.2041-5370.1996.tb01914.x

Sabin, P. (2000). The Face of Roman Battle. The Journal of Roman Studies, 90, 1-17. https://doi.org/10.2307/300198

Walbank, P. F. (1957). A Historical Commentary on Polybius. Clarendon Press. 